\title{
Indoor and outdoor allergens in Bloemfontein
}

The Free State province of South Africa is traditionally considered to be a haven for outdoor allergens such as grass pollens, which cause severe hayfever symptoms in the grass pollen season, and maize pollens, particularly in the rural areas.

In 1991 Mercer and Van Niekerk reported a house-dust mite skin-prick test positivity rate of $25.7 \%$ in an asthma clinic in Bloemfontein, ${ }^{1}$ compared with a prevalence of $80 \%$ reported in children attending an allergy clinic in coastal Cape Town. ${ }^{2}$

This issue of the SAMJ features a new study by Seedat et al. ${ }^{3}$ on indoor and outdoor allergen sensitisation in the Free State. Not only does the study identify sensitisation to a previously unrecognised outdoor allergen (the spider mite, Tetranychus urticae) in the region, but it reports that the sensitisation rate to house-dust mites in patients with allergic rhinitis is a significant $46 \%$ for Dermatophygoides pteronyssinus and $44 \%$ to D. farinae using the ImmunoCap RAST.

A second small acaralogical study by Sinclair et al. ${ }^{4}$ of housedust mite species in Bloemfontein, also published in this issue of $S A M J$, found house-dust mite in $50 \%$ of the homes investigated at some time of the year, and in $30 \%$ mites were present consistently.

The finding of high levels of sensitisation to the spider mite Tetranychus, readily explained by the widespread prevalence of the mite in Free State farms referred to by Seedat et al. ${ }^{3}$ has also been reported from the Hex River Valley in the studies of Jeebhay. ${ }^{5}$ Since many subjects sensitised to spider mite are simultaneously polysensitised to other outdoor and indoor allergens, the clinical significance of such sensitisation has yet to be studied by exposure and challenge studies. There are no vaccines available to desensitise patients to spider mites.

In contrast, immunotherapy for house-dust mite allergens is available by the sublingual and subcutaneous routes for patients sensitised to D. farinae and/or D. pteronyssinus who do not simultaneously have other significant allergen sensitisations, on a named-patient basis. For patients in the Free State who have persistent rhinitis symptoms outside the pollen season related to the indoor environment, testing for specific mite indoor allergen sensitisation is very important, both for institution of allergen avoidance measures and selection of the appropriate mite-specific avoidance measures, and for selection of the appropriate mite-specific immunotherapy vaccine to offer the patient a chance of cure.

It is interesting to note that Seedat et al. ${ }^{3}$ found that allergic subjects in the Free State who had previously lived at the coast were significantly more likely to be sensitised to mites than those who had not, emphasising the importance of history taking when selecting allergy test panels for the investigation of allergic patients.
The acaralogical studies of Sinclair et al. ${ }^{4}$ provide some insight into the variability of the presence of and therefore exposure to mites in Bloemfontein homes, and also illustrates that in some homes very high levels of mites are attained as a result of indoor microclimate factors that raise indoor humidity, such as en-suite bathrooms.

These studies suggest that the relationship between exposure, sensitisation and the expression of clinical allergic disease to house-dust mites is not a simple one and may depend not only on level of exposure but age of exposure and context of exposure.

The sensitisation rates of allergic subjects in the Free State to cockroach species such as Blatella germanica $(38 \%)$, the oriental cockroach $(28 \%)$ and Periplanata americana $(22 \%)$ are similar to the rates of sensitivity to cockroaches reported by Manjra et al. ${ }^{6}(40 \%$ in the Western Cape and Natal and $32 \%$ in the highveld of Gauteng). Monosensitisation to cockroach species (in the absence of sensitisation to house-dust mites or grass pollen) is extremely rare in the South African context, and no immunotherapy vaccines are available for cockroach desensitisation.

Studies such as these add to the growing body of published information on allergens and allergies in southern Africa. They emphasise the need for further studies and provide opportunities for curative allergen-specific immunotherapy in carefully selected patients. There is also a great need for adequate education and training of medical students and specialists in the area of regional allergies to raise the standard of allergy treatment in South Africa.

\section{P C Potter}

Allergy Diagnostic and Clinical Research Unit

University of Cape Town Lung Institute and

Groote Schuur Hospital

Cape Town

Corresponding author: P C Potter (Paul.Potter@uct.ac.za)

References

1. Mercer MJ, Van Niekerk CH. Clinical characteristics of childhood asthma. S Afr Med J 1991; 79: 77-79.

2. Potter PC, Berman D, Toerien A, Malherbe D, Weinberg EG. Clinical significance of allergen identification in the Western Cape. S Afr Med J 1991; 79: 80-84

3. Seedat RY, Claasen J, Claasen AJ, Joubert G. Mite and cockroach sensitisation in patients with allergic rhinitis in the Free State. S Afr Med J 2010; 100: 160-163 (this issue).

4. Sinclair W, Coetzee L, Joubert G. Housedust mite species in Bloemfontein. S Afr Med J 2010; 100: 164-167 (this issue).

5. Jeebhay MF, Baatjies R, Chang Y. Risk factors for allergy due to the two spotted spider mite (Tetranychus urticae) among table grape farm workers. Int Arch Allergy Immunol 2007; 144: 143-149.

6. Manjra A, Prescott R, Potter PC. Cockroach allergy in Durban. Cur Allergy Clin Immunol 1995; 8: 3-7. 